\title{
Os limites da aplicabilidade do princípio da supremacia do interesse público para os casos de desapropriação no Estado Democrático de Direito: uma análise sobre a implantação do Porto do Açu
}

The Limits of Applicability of the Principle of Supremacy of Public Interest to Cases of Expropriation in the Democratic Rule of Law: an Analysis of the Implementation of the Açu Port

Resumo: 0 princípio da supremacia do interesse público consiste no interesse da coletividade se sobrepor ao interesse do particular, sendo, dessa forma, o princípio que fundamenta o procedimento da desapropriação. Há casos de desapropriação em que os desapropriados não recebem os benefícios sociais e econômicos devidos, além de estarem sujeitos a realocação residencial para áreas distantes. Neste sentido, o objetivo da pesquisa foi realizar uma análise dos limites da aplicabilidade do princípio da supremacia do interesse público para os casos de desapropriação no Estado Democrático de Direito, tendo como pano de fundo a instalação e operação do Porto do Açu. Utilizaram-se como referências doutrinadores atuantes na área e o ordenamento jurídico brasileiro com aplicação de um estudo de caso, com base em dados secundários disponibilizados pelas Instituições de Regulação e Fiscalização. Ao final, concluiu-se que Administração Pública possui um papel fundamental na formação de uma sociedade menos desigual.

Palavras-chave: Administração Pública. Estado Democrático de Direito. Porto do Açu.
Abstract: The Principle of Supremacy of Public Interest consists in the interest of the collectivity over and above the interest of the individual, and is thus the principle that underlies the expropriation procedure. We present a case of land expropriation conducted by a state government in which the expropriated landowners did not receive the social and economic benefits owed to them for losing their land, in addition to being subject to forced residential relocation to distant areas. In this sense, the purpose of the research was to analyze the limits of the applicability of the principle of supremacy of public interest to cases of expropriation in the Democratic Rule of Law, against the backdrop of the establishment and operation of the Açu Port. We used the works of legal experts with wide knowledge of the Brazilian legal system as references to conduct a case study, based on secondary data provided by the regulatory agencies. It was concluded, then, that Public Administration has a major role in the creation of a less unequal society.

Keywords: Public Administration. Democratic Rule of Law. Açu Port.

\section{Mateus Gomes Almeida}

Graduando em Direito pela Universidade Candido Mendes (UCAM) - Campos. Pesquisador colaborador no Laboratório de Estudos do Espaço Antrópico do Centro de Ciências do Homem da Universidade Estadual do Norte Fluminense Darcy Ribeiro (UENF).E-mail: mateus_g_almeida@hotmail.com.

\section{Frank Pavan de Souza}

PhD, advogado. Engenheiro ambiental e de segurança do trabalho. Professor da Universidade Candido Mendes (UCAM) Campos. E-mail: frank@acionaconsultoria.com.br 


\section{INTRODUÇÃO}

No ano de 2007, com o início da construção do Porto do Açu, o município de São João da Barra (RJ) começou a sofrer alterações em suas estruturas demográfica, social e econômica. A população que tradicionalmente habitava $05^{\circ}$ Distrito de São João da Barra - formado, basicamente, por agricultores familiares e pescadores artesanais - foi diretamente impactada pelas desapropriações promovidas pelo governo do estado do Rio de Janeiro, manifestadamente para viabilizar a implantação do Porto do Açu e do Distrito Industrial de São João da Barra (DISJB). Este processo de desapropriação acarretou centenas de processos judiciais que permaneceram majoritariamente sem solução até 0 presente momento. Segundo Pedlowski (2012), o processo de remoção forçada das populações tradicionais que utilizavam a terra como meio de produção e reprodução social representou um golpe duro para a agricultura familiar e a pesca artesanal em São João da Barra, o que explica a oposição local ao Porto do Açu bem como os conflitos sociais que se alternam em formas abertas e latentes de confronto.

Os tipos de e intensidade dos impactos (i.e., sociais, econômicos e ambientais) que marcam a implantação de um dado projeto econômico são influenciados diretamente pelo papel que a administração pública exerce em uma sociedade, seja desempenhando sua função de fomento público, seja de intervenção na ordem social vigente. Nesse sentido, o presente artigo tem como objetivo analisar os limites da aplicabilidade do princípio da supremacia do interesse público para os casos de desapropriação no Estado Democrático de Direito, tendo como pano de fundo a instalação e o funcionamento do Porto do Açu. Segundo Di Pietro (2010), o princípio da supremacia do interesse público está na origem do instituto da desapropriação, encontrando limites em diversos princípios constitucionais e administrativos, os quais visam garantir a legalidade dos atos administrativos e cuja finalidade é atender ao interesse público. Para avaliar se este princípio e seus limites foram observados no caso do Porto do Açu, utilizamos como referências trabalhos de doutrinadores atuantes na área e 0 ordenamento jurídico brasileiro, para conduzir um estudo de caso apoiado em dados secundários disponibilizados pelas instituições de regulação e fiscalização.

Este artigo está dividido em cinco partes. Na primeira, é apresentada uma abordagem sobre o direito administrativo no Estado Democrático de Direito concomitantemente às funções dos princípios administrativos. Na segunda parte, é elaborada uma análise sobre o princípio da supremacia do interesse público e desapropriação. A terceira apresenta os resultados de uma análise do processo de desapropriação de terra realizada pelo governo estadual do Rio de Janeiro para viabilizar a implantação do Porto do Açu e do Distrito Industrial do Rio de São João da Barra. Na quarta, é apresentada uma discussão sobre o processo de desapropriação de terras bem como o papel do princípio da supremacia do interesse público. Finalmente, na quinta parte, são apresentadas as principais considerações e conclusões acerca do caso representado pelo processo de desapropriação de terras promovido no $5^{\circ}$ Distrito de São João da Barra.

\section{O DIREITO ADMINISTRATIVO NO ESTADO DEMOCRÁTICO DE DIREITO}

0 Direito Administrativo, concomitante ao Direito Constitucional, estabeleceu-se como um avanço fundamental nas garantias de direitos e liberdades individuais na sociedade capitalista. Segundo Gabardo (2010), onde antes prevaleciam interesses personalistas, na figura do soberano absoluto das monarquias absolutistas, a partir da Revolução Francesa, começou a prevalecer a noção de vontade geral, dando início às evoluções na sociedade moderna. Nesse sentido, Di Pietro (2019, p. 54) postula que:

[...] a formação do Direito Administrativo, como ramo autônomo, teve início juntamente com o direito constitucional e outros ramos do direito público, a partir do momento em que começou a desenvolver-se - já na fase do Estado Moderno - o conceito de Estado de Direito, estruturado sobre o princípio da legalidade [...]

Assim sendo, desde o final do século XVII até os dias de hoje, o Direito Administrativo passou por diversas transformações, sendo caracterizado pelo binômio autoridade-liberdade. Segundo Di Pietro (2010), o Direito Administrativo possui prerrogativas que garantem a sua autoridade para cumprir sua função primordial de interesse da coletividade e do bem-estar social bem como o dever de garantir os direitos fundamentais dos cidadãos contra os abusos de poder. Isto faria com que fosse cumprida a função pública no Estado Democrático de Direito. Por sua vez, Mello (2010) afirma que o Direito Administrativo se erige sobre o binômio prerrogativas da Administração e direitos dos administrados. É o entrosamento destes dois termos que the delineia a fisionomia. 
No Estado Democrático de Direito, o Direito Administrativo é aquele que observa uma série de princípios que visam a dar sentido à administração pensando na ideia de bem coletivo e não em um interesse pessoal, seja da figura do administrador público, seja de terceiro que possa lhe interessar. De acordo com Nohara (2010), uma significativa diferença do Estado democrático em relação ao Estado autoritário é que, enquanto o primeiro visa a tomar medidas legitimadas num consenso social, o último toma decisões pautadas em interesses individuais ou de pequenos grupos.

Ao definir o Direito Administrativo como sendo um instituto que assegura uma série de direitos aos indivíduos, é preciso trazer à baila alguns dos seus princípios que conferem uma série de deveres e poderes à Administração Pública. Essa combinação entre deveres e direitos configura os chamados "Princípios Expressos", que estão explícitos no caput do art. 37 da Constituição Federal de 1988 - "Art. 37. A administração pública direta e indireta de qualquer dos Poderes da União, dos Estados, do Distrito Federal e dos Municípios obedecerá aos princípios de legalidade, impessoalidade, moralidade, publicidade e eficiência". Nesse contexto, existem ainda os chamados princípios implícitos, que não estão previstos na Constituição Federal. Estes princípios implícitos incluem: o princípio da supremacia do interesse público sobre o privado; 0 princípio da continuidade do serviço público; o princípio da indisponibilidade do interesse público; o princípio da autotutela; e o princípio da proporcionalidade.

0 princípio da legalidade no Direito Administrativo está relacionado com o dever do administrador público de observar todo o bloco da juridicidade, ou seja, observar o direito como um todo, incluindo todos os mandamentos legais que vigoram dentro do território nacional, como tratados internacionais, leis constitucionais e infraconstitucionais, decretos, medidas provisórias etc. Desta forma, Mazza (2019, p. 110) afırma que:

Inerente ao Estado de Direito, o princípio da legalidade representa a subordinação da Administração Pública à vontade popular. 0 exercício da função administrativa não pode ser pautado pela vontade da Administração ou dos agentes públicos, mas deve obrigatoriamente respeitar a vontade da lei.

Já no que se refere ao princípio da impessoalidade, o administrador não pode agir com o intuito de favorecer ou prejudicar alguém, ele deve agir em nome do interesse público e do coletivo. Assim sendo, a impessoalidade é a ausência de rosto em relação à administração e de sobrenome em relação aos administrados. Mazza (2019) afırma que o princípio da impessoalidade estabelece um dever de imparcialidade na defesa do interesse público, impedindo discriminações (perseguições) e privilégios (favoritismo) indevidamente dispensados a particulares no exercício da função administrativa.

O princípio da moralidade é aquele em que a conduta do administrador público está baseada na boa-fé, na honestidade e na lealdade. Se ficar constatado o contrário, o administrador público estará violando esse princípio, e a violação deste princípio implicará a violação do próprio Direito (MELLO,2010).

Finalmente, o princípio da supremacia do interesse público é aquele que se aplica toda vez que houver uma colisão entre o interesse da coletividade e o interesse privado, sendo a administração obrigada a fazer valer o interesse público. Desta forma, a supremacia do interesse público significa que os interesses da coletividade são mais importantes que os interesses individuais, razão pela qual a Administração, como defensora dos interesses públicos, recebe da lei poderes especiais não extensivos aos particulares (MAZZA, 2019, p. 101).

\section{O PRINCÍPIO DA SUPREMACIA DO INTERESSE PÚBLICO E DESAPROPRIAÇÃO}

A Administração Pública, na figura do poder executivo, tem o dever de desempenhar quatro atividades fundamentais: prestação de serviço público; fomento público; exercício do poder de polícia; e intervenção na ordem econômica e social. Para Di Pietro (2010), o princípio da supremacia do interesse público é que fundamenta a maioria das quatro atividades supracitadas. Assim é a partir da necessidade de uma sociedade mais justa, em que o Estado pode assegurar e ofertar uma série de direitos aos cidadãos, nos quais o princípio da supremacia do interesse público se baseia. Nesse sentido, Di Pietro (2010, p. 92) afirma que:

[...] com o Estado Social, o interesse público a ser alcançado pelo direito administrativo humaniza-se na medida em que passa a ocupar-se não só com os bens materiais que a liberdade de iniciativa almeja, mas com valores considerados essenciais à existência digna; quer-se liberdade com dignidade, 0 que exige maior intervenção do Estado para diminuir as desigualdades sociais e levar a toda a coletividade o bem-estar-social [...] 
A ideia de interesse público é a base do Direito Administrativo. Entretanto, para que todos esses poderes atribuídos à Administração Pública sejam exercidos de maneira idônea, os princípios administrativos devem ser respeitados. Sendo assim, Di Pietro (2010) argumenta que "a defesa do interesse público corresponde ao próprio fim do Estado e que o Estado tem que defender os interesses da coletividade". Além disso, o Estado tem que fazer prevalecer o interesse público em detrimento do individual nas hipóteses previstas pelo ordenamento jurídico. De forma similar, Gabardo (2017, p. 114) afırma que "o reconhecimento de privilégios para a Administração Pública na sua atuação encontra limites insuperáveis na legalidade bem como faz da aplicação do princípio da supremacia do interesse público não só um poder, mas também um dever do Estado".

Em uma instância particular - como no caso da realização de processos de desapropriação (ou expropriação) - tendo como fundamento o princípio da supremacia do interesse público sobre o privado, o Estado poderá intervir na propriedade privada desde que respaldado na lei. A Constituição Federal, em seu artigo 5 , XXIV, prevê o procedimento da desapropriação com base em certos fundamentos. Assim, no art. 50, XXIV, a Constituição Federal determina que "a lei estabelecerá o procedimento para desapropriação por necessidade ou utilidade pública, ou por interesse social, mediante justa e prévia indenização em dinheiro, ressalvados os casos previstos nesta Constituição". Segundo Mazza (2019, p. 920),

Desapropriação ou expropriação é o procedimento administrativo pelo qual o Estado transforma compulsoriamente bem de terceiro em propriedade pública, pagando indenização prévia, justa e em dinheiro. Trata-se da modalidade mais agressiva de intervenção do Estado na propriedade privada, na medida em que suprime o domínio do bem expropriado, razão pela qual é o único instrumento de intervenção que garante prévia indenização. (art. 50, XXIV, da CF).

Na legislação infraconstitucional, o Decreto-lei n. ${ }^{0}$ 3365/41 é utilizado quando a desapropriação for por utilidade ou necessidade pública. Já o Decreto-lei n. ${ }^{0}$ 4132/62 é utilizado quando a desapropriação for por interesse social. É importante notar que, na necessidade pública, a desapropriação é a única medida ou a única forma para se alcançar o interesse público e coletivo. Já na utilidade pública, a desapropriação é aquela que se mostra como sendo a mais conveniente, a mais oportuna para se alcançar o interesse público.

0 procedimento da desapropriação pode ser classificado de formas diferentes quanto à sua legalidade, dependen- do se o ato foi lícito ou ilícito. A desapropriação direta é aquela feita de maneira lícita, respeitando o devido processo legal e atendendo às regras impostas pela legislação infraconstitucional. Já a desapropriação indireta é considerada ilícita, porque se trata de uma invasão do Estado na propriedade alheia. Em outras palavras, a desapropriação indireta é a aquisição da propriedade privada sem a observância dos requisitos constitucionais e legais. Nesse sentido, a desapropriação indireta se trata de um ato ilícito e violador da ordem jurídica, e do devido processo legal. De acordo com Benzos (2016, p.50): "a desapropriação indireta, além de configurar um esbulho possessório, vulnera frontalmente a Constituição Federal, que condiciona a desapropriação ao pagamento de prévia e justa indenização".

\section{UMA ANÁLISE DO PROCESSO DE DESAPROPRIAÇÃO PARA A IMPLANTAÇÃO DO COMPLEXO PORTUÁRIO DO AÇU}

$05^{\circ}$ Distrito do Açu, que está localizado no município de São João da Barra, norte do estado, passou por alterações em suas estruturas geográfica, social e econômica nos últimos quinze anos. Em 2007, com o início da construção do Porto do Açu, a região passou a ser promessa de desenvolvimento econômico e social.

Em sua versão inicial, a construção do Porto do Açu previa, também, a implantação de um complexo industrial. Idealizado pelo empresário Eike Batista, o Complexo Logístico Industrial do Porto do Açu (Clipa) foi projetado para ser construído na área contígua ao Porto do Açu. 0 Clipa tinha como objetivo permitir a instalação de um complexo siderúrgico, uma usina termelétrica, um polo metalomecânico, uma unidade de pelotização de minério de ferro, áreas para armazenamento de granéis líquidos e processamento de petróleo, além de uma unidade de construção naval no local (Pacheco, 2017). Segundo a seção fluminense da Associação dos Geógrafos do Brasil (AGB), o Clipa seria implementado com base em uma parceria público-privada entre a Companhia de Desenvolvimento Industrial do Estado do Rio de Janeiro (Codin) e a LLX Açu Operações Portuárias S.A., empresa-membro da holding formada pelo Grupo EBX.

Em 2008, o Governo do estado do Rio de Janeiro publicou uma série de decretos que declaravam uma área de 7521 hectares de utilidade pública, a qual deveria ser desapropriada. Essa área, de acordo com a AGB (2011), era ocupada basicamente por agricultores familiares, que, 
por força dos decretos, deveriam retirar-se de suas terras para dar lugar ao projeto de construção do Clipa.

No que tange às leis utilizadas para a implantação do projeto de construção do Clipa, a Prefeitura Municipal de São João da Barra publicou duas leis municipais fundamentais para dar respaldo jurídico ao início do processo de desapropriação. 0 Plano Diretor Municipal, disposto na Lei Municipal $n^{0}$ 50/2006, e a Lei de Macrozoneamento, Lei Municipal n. 115/2008 (alteradas posteriormente pela Lei no 357/2015) converteram uma área predominantemente rural em área de macrozona de desenvolvimento econômico.

O Estudo de Impacto Ambiental (ECOLOGUS, 2011) desenvolvido pela LLX apresenta todas as leis estaduais e municipais que foram utilizadas para a implantação do projeto de construção do Clipa. 0 documento comprova que foi por meio das leis municipais (Plano Diretor Municipal e Lei de Macrozoneamento) que o Governo do estado do Rio de Janeiro obteve suporte legal para promulgar os decretos expropriatórios. 0 ElA aponta que "de acordo com a lei de Zoneamento e Uso do Solo, editada pelo Município de São João da Barra, a área de implantação do empreendimento está integralmente inserida em Zona de Expansão Industrial, conforme previsto na lei de Zoneamento Municipal".

Por sua vez, os Decretos Estaduais n. ${ }^{0} 41.584$ e n. ${ }^{0} 41.585$, de 5 de dezembro de 2008; n. ${ }^{0} 41.915$ e n. ${ }^{0}$ 41.916, de 19 de junho de 2009; e n. ${ }^{0} 41.998$, de agosto de 2009, foram publicados com fundamento na utilidade pública (Lei n. ${ }^{\circ}$ 3365/1941) e em favor da Codin. Além disso, o Decreto $n .{ }^{\circ}$ 42.422/10 delegou à Codin a competência para praticar os atos, de natureza administrativa ou judicial, necessários à implantação do DISJB.

Logo após a promulgação dos decretos, a Codin assinou com a LLX Logística, um documento de promessa de compra e venda relativa à parte dos imóveis do DISJB. Com base nessa promessa, a LLX adquiriu direitos relativos à propriedade de aproximadamente 4.100 hectares localizados dentro do Clipa, sendo que, com essa aquisição, a LLX passou a ser proprietária de 7.000 hectares de um total de 9.000 hectares destinados à instalação de áreas industriais e comerciais. Esse contrato indicava que o estado (por intermédio da Codin, enquanto ente que desapropriou, transferia para a LLX a titularidade das terras desapropriadas.

Com os decretos, baixados pelo governador Sérgio Cabral Filho, foram desapropriados $90 \%$ das terras do Açu, atingindo diretamente mais de 1.500 famílias que tradicionalmente habitavam a região (Costa, 2017). 0 processo de desapropriação alterou de maneira drástica a dinâmica territorial da região, resultando em conflitos e processos judiciais que duram até os dias de hoje.
A Associação dos Proprietários Rurais e Imóveis de São João da Barra (ASPRIM), que representou os moradores locais atingidos, relata uma série de violações de direitos decorrentes do processo de desapropriação feito pelo governo estadual. Estas violações incluíram desde ameaças e intimidações até a invasão de suas terras sem mandado judicial. Em relação ao processo de desapropriação, a AGB (2011, p. 45) apontou que:

No caso das terras que estão sendo desapropriadas pela CODIN, os problemas envolvem a forma de notificação, erros de vistoria, subavaliação e assédio moral. A ASPRIM relata que as famílias têm sido intimidadas por agentes de segurança privada, contratados pela LLX, pela polícia militar do $8^{\circ}$ Batalhão de Campos e por ações criminosas, como o caso dos agricultores que tiveram suas terras e lavouras invadidas e destruídas em pleno final de semana e no período noturno.

Passada cerca de uma década do auge do processo de desapropriação de terras do $5^{\circ}$ Distrito de São João da Barra, ainda não há notícias de que o DISJB será construído nas áreas desapropriadas. Em fevereiro de 2017, o Ministério Público Federal (MPF) denunciou, à $7^{\text {a }}$ Vara Federal, 0 empresário Eike Batista, o ex-governador Sérgio Cabral e outras sete pessoas por corrupção e lavagem de dinheiro (MPF, 2017). De acordo com a denúncia apresentada pelo MPF, o governador utilizava seu cargo público para favorecer interesses privados e recebia propina em troca. A denúncia diz que:

Como se vê, denunciado SERGIO CABRAL, no exercício do seu mandato como governador do estado do Rio de Janeiro, solicitou e aceitou vantagem indevida para exercer o seu cargo com especial atenção para os interesses privados do denunciado EIKEBATISTA. Estão plenamente configurados os crimes de corrupção passiva e ativa porquanto resta claro que o conjunto de funções exercido pelo agente público em questão está relacionado com os interesses privados do particular, isto é, pode-se aferir extreme de dúvidas a relação de mercancia que tem por objeto a função pública exercida pela então maior autoridade do Poder Executivo estadual. (INQUÉRITO POLICIAL n ${ }^{0}$ 0501634-09.2017.4.02.5101. p.32)

A denúncia narrava ainda que as desapropriações para a instalação dos empreendimentos ligados ao Porto do Açu - entre outros empreendimentos que o empresário Eike Batista levava a efeito no estado do Rio na época - foram fundamentais para garantir ao ex-governador Sergio Cabral a quantia de mais de US\$ 16 milhões, aproximadamente 
$\mathrm{R} \$ 40$ milhões (de acordo com o valor do dólar à época), como forma de vantagem indevida por facilitar e permitir que esses empreendimentos acontecessem mesmo que à revelia dos direitos de milhares de famílias afetadas pelas desapropriações.

Posteriormente, em 2019, dois anos e três meses depois de ter sido preso, o ex-governador Sérgio Cabral assumiu, em depoimento ao Ministério Público, que recebeu propina de Eike Batista para realizar as desapropriações para a construção do Complexo Industrial do Porto do Açu (Ribeiro e Gomes, 2019).

Atualmente, após mais de dez anos dos decretos expropriatórios, segundo dados da Defensoria Pública do Estado do Rio de Janeiro, dos 229 agricultores alvos de processo de desapropriação ajuizados na $2^{\text {a }}$ Vara da Comarca de São João da Barra pela Codin, menos de $5 \%$ receberam o valor total das indenizações (DEFENSORIA PÚBLICA DO RIO DE JANEIRO, 2017). Além deles, um grupo de menos de 10\% obteve $80 \%$ da quantia à qual têm direito, a Defensoria aponta também que, além das 229 ações em trâmite na $2^{\text {a }}$ Vara, há outras tantas em curso no Fórum de São João da Barra, e elas totalizam 476 processos de desapropriação.

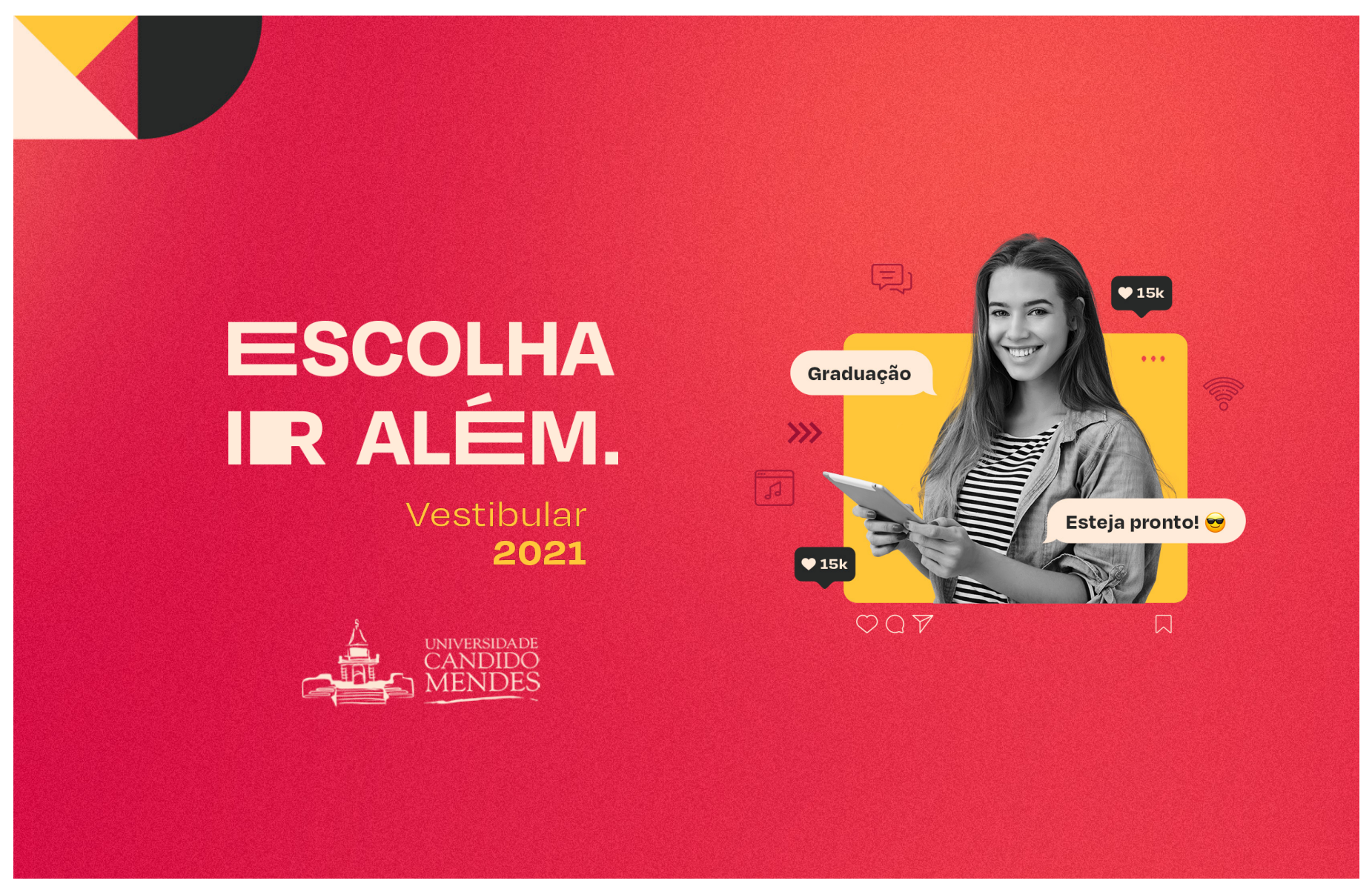


CONSIDERAÇÕES SOBRE 0 PROCESSO DE DESAPROPRIAÇÃO E $O$ PAPEL DO PRINCÍPIO DA SUPREMACIA DO INTERESSE PÚBLICO

A análise do processo de desapropriação para viabilizar a construção do Clipa levanta questões importantes sobre a natureza dos atos administrativos do poder executivo na figura do Governador do estado do Rio de Janeiro (Pedlowski, 2012). Entre os aspectos relevantes que merecem ser investigados, estão a legalidade das desapropriações especialmente no tocante ao respeito aos princípios da legalidade, impessoalidade e moralidade - bem como 0 real interesse público desses atos.

Além disso é possível apontar que, em se observando o caso das desapropriações realizadas no $5^{\circ}$ Distrito de São João Barra, fica evidente que foram violados vários princípios constitucionais do direito administrativo. Um exemplo disso é o do princípio da supremacia do interesse público utilizado para favorecimento privado nas figuras do Governador Sérgio Cabral e do empresário Eike Batista. 0 fato é que fica aparente que o processo de desapropriação teve por finalidade legitimar a venda das terras expropriadas pelo estado para o empresário, causando consequências sociais gravíssimas aos habitantes tradicionais do $5^{\circ}$ Distrito de São João da Barra, que tiveram suas memórias e histórias destruídas para o beneficiamento de interesses corporativos, no caso o do Grupo EBX. Em entrevista feita por Alvarenga (2013), os moradores relataram a dificuldade e a tristeza de deixarem as terras em que moravam há décadas, principalmente por terem de abrir mão de suas tradições e costumes para dar lugar ao complexo portuário e industrial.

Segundo Santos (2015), para determinadas populações, 0 território seria como uma identidade, a base do trabalho, das trocas materiais e espirituais, do qual se extrai a ideia de pertencimento àquele espaço, tornando-o parte de suas próprias vidas. Para Nohara (2010, p. 131),

A atuação do administrador não pode se desviar do princípio da supremacia do interesse público. Enquanto o particular age na consecução de seus interesses, o agente público não deve dar maior importância aos interesses particulares, sejam os próprios ou os de terceiros, em detrimento da consecução do interesse público, sob pena de desvio de finalidade e da caracterização da improbidade administrativa, entre outras consequências possíveis
Outro aspecto que merece ser analisado é se o princípio administrativo da supremacia do interesse público - que fundamenta o instituto da desapropriação - foi corretamente aplicado ou se o que houve, objetivamente, foi sua má utilização pelo estado.

Segundo a doutrina majoritária, o problema não é do princípio, mas sim da forma como ele é aplicado. Nesse sentido, Gabardo (2017, p. 115) afirma que "o simples fato de o princípio da supremacia ser usado como argumento (ou álibi) de certos atos arbitrários não significa de modo algum a deturpação de sua essência ou sua força ética e normativa. Além disso, Di Pietro (2010) argumenta que o princípio da supremacia do interesse público protege os direitos fundamentais, e não os coloca em risco. Nesse entendimento, o princípio da supremacia serve para proteger interesses de diferentes camadas sociais e, em paralelo a esse princípio, nascerem os direitos sociais e econômicos.

Em um contexto de globalização e enfraquecimento do Estado, defender o princípio da supremacia do interesse público é fundamental. Também é importante pontuar que o uso deste princípio para justificar a ocorrência de condutas imorais de agentes públicos e de empresários - que se utilizam do Estado e de sua força normativa para beneficiamento próprio -, na verdade, não contribui para que o interesse público seja efetivamente assegurado. Segundo Nohara (2010, p. 141):

[...] não se ignora que o Estado esteja permeado por interesses de grupos particulares que não o incentivam a buscar meios efetivos de acessar alguma espécie de consenso social acerca do que seja o interesse público em determinadas situações concretas ou mesmo que tal movimento venha de imposições de atores externos ao cenário nacional, tendo em vista a globalização econômica.

A desconstrução da supremacia do interesse público, portanto, pode servir a um discurso ultraliberal, no sentido de restaurar a noção de liberdade incondicionada do particular em buscar os meios e fins de sua conduta, sem a "indevida" intervenção estatal, como pode servir também ao discurso neoliberal, que objetiva impor restrições ao intervencionismo estatal na economia, limitando-0 a setores tidos como "imprescindíveis", no intuito de restaurar um projeto de Estado mínimo [...].

Por outro lado, Santos (2015) sugere que, no processo de globalização econômica, as empresas são exibidas como salvadoras dos lugares, pois seriam as únicas capazes de trazer progresso, emprego e modernidade, surgindo daí a crença da sua indispensabilidade. Com base nessa falácia, 
as corporações chantageiam o poder público para que suas demandas sejam atendidas, pois, do contrário, ameaçam abandonar determinados projetos em prol de outros. É a partir dessa lógica que se dá a ingovernabilidade. Nesse sentido, Bauman (1999, p.74) afirma que:

[...]. No cabaré da globalização, o Estado passa por um strip-tease e no final do espetáculo é deixado apenas com as necessidades básicas: seu poder de repressão. Com sua base material destruída, sua soberania e independência anuladas, sua classe política apagada, a nação-estado torna-se um mero serviço de segurança para as megaempresas...

Dessa forma, o princípio da supremacia do interesse público - como princípio que dá base à administração pública - se faz mais do que necessário na construção de um Estado Democrático de Direito e na construção de uma sociedade menos desigual. Isso se dá porque, conforme Di Pietro (2010, p. 101) afirma, "o direito administrativo é um dos principais instrumentos de aplicação da Constituição". Di Pietro sugere ainda que, no caso da Constituição Federal de 1988, está explicito que ela não enseja apenas a proteção do interesse econômico, pois em diversos de seus capítulos há a presença de elementos que a tornam um documento que visa a construir uma sociedade mais democrática e pluralista.

\section{CONSIDERAÇÕES FINAIS}

0 caso do Porto do Açu, trazido para discussão no presente artigo, deixa claro como agentes públicos e empresários se utilizam de mecanismos supostamente legais para cometer uma série de ilegalidades, causando, dessa forma, embaraços sobre o próprio papel e a importância do princípio da supremacia do interesse público - que encontra seus limites nos princípios constitucionais e administrativos - e, consequentemente, da Administração Pública na construção de um Estado Democrático de Direito.
A Administração Pública possui um papel fundamental na formação de uma sociedade menos desigual. Em tempos de negação da política, de negação do papel do Estado frente aos desafios impostos pelo mundo contemporâneo, faz-se necessária a defesa de uma Administração Pública que valorize e respeite os princípios constitucionais e administrativos, buscando, dessa forma, diminuir as desigualdades e solucionar problemas que são inerentes a qualquer sociedade.

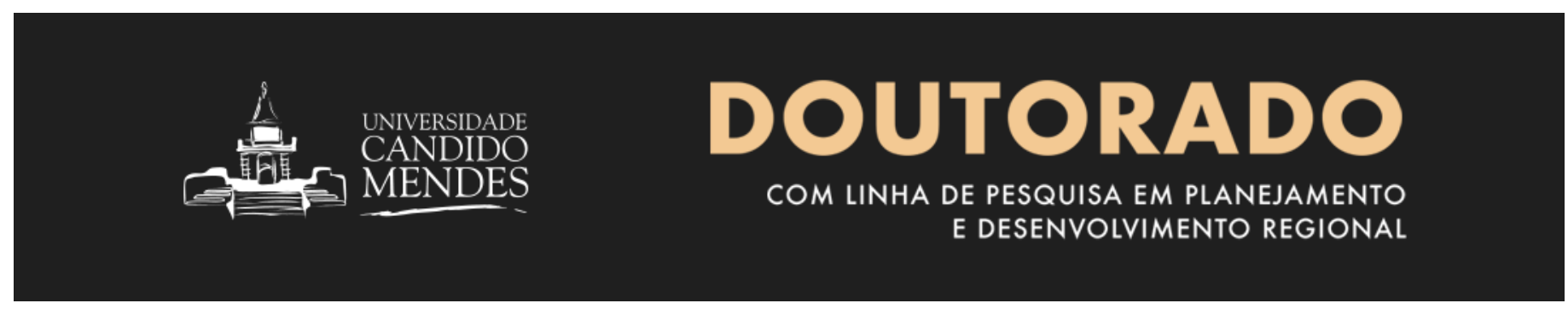




\section{Referências}

ASSOCIACÃ̃O DE GEÓGRAFOS BRASILEIROS (AGB). Relatório dos impactos socioambientais do Complexo Industrial-Portuário do Açu. Rio de Janeiro: AGB, 2011. Acesso em: https://docplayer.com.br/561109-Relatorio-dos-impactos-socioambientais-do-complexo-industrial-portuario-do-acu-i. html. Acesso em: 15 out. 2020.

ALVARENGA, Felipe. Os deserdados do desenvolvimento: o caso da implantação do complexo portuário e industrial do açu e seus impactos socioterritoriais. Campos dos Goytacazes: UENF, 2013.

BAUMAN, Zygmunt. Globalização: as consequências humanas. Rio de Janeiro: Zahar, 1999.

BENZOS, Clovis. Aspectos jurídicos da indenização na desapropriação. 2. ed. Belo Horizonte: Fórum, 2016.

BRASIL. Constituição da República Federativa do Brasil de 1988. Disponível em: http://www.planalto.gov.br/ccivil_03/constituicao/constituicao.htm. Acesso em: 08 out. 2020.

COSTA, Ana Maria. 0 processo de expropriação das terras do Açu e a trajetória de lutas dos camponeses impactados pelo projeto Minas-Rio.

2018. 266 f. Tese (Doutorado em: Serviço Social) - Escola de Serviço Social, UERJ, Rio de Janeiro, 2018.

COMUNICADO PROMESSA DE COMPRA E VENDA LLX, 06/08/2010.

DEFENSORIA PÚBLICA DO RIO DE JANEIRO. Açu: de 229 agricultores, menos de 5\% receberam indenização integral. 12 de junho de 2017 Disponível em: http://www.defensoria.rj.def.br/noticia/detalhes/4340-Acu-de-229-agricultores-menos-de-5-receberam-indenizacao-integral. Acesso em: 20 set. 2020.

DI PIETRO, Maria Sylvia Zanella. Direito administrativo. 32. ed. Rio de Janeiro: Forense, 2019.

DI PIETRO, Maria Sylvia Zanella. 0 princípio da supremacia do interesse público: sobrevivência diante dos ideais do neoliberalismo. Supremacia do interesse público e outros temas relevantes do direito administrativo. São Paulo: Atlas, 2010. p. 85-102.

ECOLOGUS. Estudo de Impacto Ambiental - ElA. Infraestruturas do Distrito Industrial de São João da Barra Maio, 2011. Disponível em: http://ceivap. org.br/downloads/eia-rima-distrito-industrial-de-sao-joao-da-barra.pdf . Acesso em: 8 out. 2020.

GABARDO, Emerson. $\mathbf{0}$ suposto caráter autoritário da supremacia do interesse público e das origens do direito administrativo: uma crítica da crítica. Supremacia do interesse público e outros temas relevantes do direito administrativo. São Paulo: Atlas, 2010.p. 13-61.

GABARDO, Emerson. O princípio da supremacia do interesse público sobre o interesse privado como fundamento do Direito Administrativo Social. Revista de Investigações Constitucionais, Curitiba, v. 4, 2017.

MAZZA, Alexandre. Manual de direito administrativo. 9. ed. São Paulo: Saraiva Educação, 2019.

MELLO, Celso Bandeira de. Curso de direito administrativo. 27. ed. São Paulo: Malheiros Editores, 2010.

MINISTÉRIO PÚBLICO FEDERAL (MPF). Lava Jato: MPF/RJ denuncia Sérgio Cabral, Eike Batista e outros sete. 10 fev. 2017. Disponível em: http://www. mpf.mp.br/rj/sala-de-imprensa/noticias-rj/lava-jato-mpf-rj-denuncia-sergio-cabral-eike-batista-e-outros-sete. Acesso em: 8 out. 2020.

NOHARA, Patrícia Irene. Reflexões críticas acerca da tentativa de desconstrução do sentido da supremacia do interesse público no direito administrativo. Supremacia do interesse público e outros temas relevantes do direito administrativo São Paulo: Atlas, 2010. p.120-152.

PACHECO, Wedson Felipe Cabral. Porto do Açu, entre as forças de conservação e modernidade. In: MARAFON, G.J.; RIBEIRO, M.A. (org.) Revisitando o território fluminense, VI [online]. Rio de Janeiro: EDUERJ, 2017, pp. 275-290. ISBN: 978-85-7511-457-5.

PEDLOWSKI, Marcos Antonio. When the state becomes the land grabber: violence and dispossession in the name of "development" in Brazil. Journal of Latin American Geography, v. 12, n. 3, p. 91-111, 2013.

PREFEITURA MUNICIPAL DE SÃO JOÃO DA BARRA. Leis Municipais. São João da Barra, 2020. Disponível em: http://www.sjb.rj.gov.br/leis. Acesso em: 20/10/2020

RIBEIRO, Lilian; GOMES, Marcelo. Sérgio Cabral admite pela primeira vez ao MPF que recebeu propina durante seu governo no RJ. G1, Rio de Janeiro, 25 fevereiro 2019. Disponível em: https://g1.globo.com/rj/rio-de-janeiro/noticia/2019/02/25/sergio-cabral-admite-pela-primeira-vez-ao-mpf-querecebeu-propina-durante-seu-governo-no-rj.ghtml. Acesso em: 10 out. 2020.

SANTOS, Milton. Por uma outra globalização: do pensamento único à consciência universal. 24. ed. Rio de Janeiro: Record, 2015. 